\title{
Spotlight on Women of Color in STEM
}

Catalina Flores

The University of Akron

I am not free while any woman is unfree, even when her shackles are very different from my own.

- Audre Lorde

The focal article by Miner et al. (2018) convincingly argues that industrial and organizational (I-O) psychology professionals share a responsibility to adopt a social-structural perspective in understanding why women are underrepresented in science, technology, engineering, and mathematics (STEM) fields. This approach offers the best path forward for explaining the disparity and improving the attraction and retention of women in these fields (Miner et al., 2018). In conjunction with the approach described, a deliberate effort to cast a spotlight on women of color is necessary, as they are the most marginalized, yet are often excluded from conversations about gender equality.

By discussing gender alone without an intentional focus on issues of race and ethnicity, we risk falling into a pitfall of progressive movementsof taking a White perspective as a default and excluding women of color. Thus, an intersectional lens is needed that focuses on the interplay among various complex identities, such as race, gender, and class, rather than examining them as separate (Crenshaw, 1991; Lorde, 1980). By considering the gender disparity in STEM from social-structural and intersectional perspectives simultaneously, we gain a more complete understanding of the issues of women in STEM and position ourselves toward building more inclusive solutions.

\section{Recognizing the Difference: The Numbers}

The focal article highlights clear evidence demonstrating the underrepresentation of women in STEM fields. Additionally, those in certain racial and ethnic groups (Black, Hispanic/Latino, and American Indian or Alaska Native individuals) are also underrepresented in STEM. As mentioned, the numbers are especially dim for women of color, particularly those

Catalina Flores, Department of Psychology, The University of Akron.

Correspondence concerning this article should be addressed to Catalina Flores, The University of Akron, Department of Psychology, Akron, OH 44325. E-mail: cf45@zips.uakron.edu 
underrepresented minority women. Women of color make up less than 1 in 10 of the STEM workforce (National Science Foundation [NSF], 2015). Although underrepresented minority women earn a higher percentage of STEM degrees than underrepresented minority men at each degree level, they are outnumbered in the STEM workforce compared to those men, making up less than $4 \%$ of the total workforce (NSF, 2015).

Most strikingly, in 2015, unemployment rates were higher for underrepresented minority women than for all the remaining scientists and engineers combined (NSF, 2015). In contrast, the trends in degree attainment are more hopeful, as the percentage of women of color earning STEM degrees has more than doubled over the past 20 years. Taken together, this may indicate that alongside efforts to promote entry into STEM fields, a focus on retention is especially important. We need to continue working toward an understanding of the unique experiences and challenges that women of color face, in order to effectively promote fulfilling and successful careers in STEM.

\section{Transforming Silence Into Language: An Intersectional Perspective}

People belong to multiple social categories, which can each affect their interactions in society and in the workplace. An intersectional perspective in psychology focuses on the multitude of identities individuals hold, which are each are associated with social positions and power dynamics (such as race, gender, sexual identity, and class; Rosenthal, 2016). Because of these intersections, people have a variety of experiences with privilege and oppression across different contexts. It is important to recognize this when studying gender, because these other components and identities have a significant effect on women's reality.

Studying gender in isolation from other identities is problematic for several reasons. First, it oversimplifies the intricate issues at hand. The experiences of White and Black women may be widely discrepant in a way that researchers would miss by looking for a main effect of gender, as opposed to an interaction between race and gender. Second, scholarship on gender has historically used White women as the focal group. Without an explicit consideration of race, we perpetuate this bias in which Whites are the defining group for our studies; theories are formed and validated on mainly White samples and the generalizability to others is not questioned (Nkomo, 1992). There is a significant literature base to support the notion that there are distinct societal factors at play in the attraction and retention of women of color in STEM.

This perspective is especially important because of the current societal zeitgeist. Scholars note that American society is currently in an "awkward historical moment" regarding race relations (Rockquemore, Brunsma, 
\& Delgado, 2009). Despite significant advancement toward racial equality, persistent factors at multiple levels of analysis (e.g., individual prejudice, societal structures) continue to uphold inequalities affecting people of color. At the same time, attitudes toward the state of affairs are disparate. For example, a recent survey indicated that most White Americans report that Whites are victims of racial discrimination (NPR, 2017).

\section{The House of Difference: Social-Structural Issues for Women of Color in STEM}

The social-structural lens advocates for attention to macrolevel influences on gender inequality, including how society perpetuates the oppression of women (Miner et al., 2018). With this, we can also examine how society collectively upholds racial hierarchies favoring Whites over people of color, leaving women of color in a position of double jeopardy. Both social constructionism and social exchange theories can be applied to understand the societal influence on the status and treatment of women of color in STEM.

Several more specific areas of research can also speak to this perspective. The following topics are not meant to constitute a comprehensive review, but highlight several themes that can serve as exemplars of the value-added from an intersectional perspective. These issues focus more on the dynamics within STEM careers over the components of attraction and entry, but all aspects are interconnected in the real world. For instance, the experience of a Latina physicist who leaves the field due to harassment will impact the perceptions of those in her social network and may dissuade someone else who was considering the same career.

\section{The Tightrope}

The tightrope reflects the experience that women feel they need to carefully monitor their behavior to meet stringent expectations or prescribed stereotypes (Cuddy, Fiske, \& Glick, 2004). Women in STEM struggle with the fact that their field is seen as masculine, but they are expected to demonstrate feminine qualities, and acting in line with masculine work norms can lead to backlash. Recent studies focusing on women of color reveal additional challenges with navigating expectations based on both race and gender (Williams, Phillips, \& Hall, 2014). Specifically, Asian-American female scientists are more likely than White scientists to report backlash for being assertive and self-promoting, and are more frequently pressured into traditionally feminine roles at work. Latina scientists are more likely to be seen as angry or emotional when they behave assertively, and are expected by their colleagues to take on more office housework. Black women are allowed more leeway in behaving in dominant ways to some extent, but also risk being seen as the "angry Black woman" (Williams et al., 2014). 


\section{Double Consciousness}

Borrowing from African-American studies, DuBois's (1961) concept of double consciousness has been used to describe how women of color grapple with their identity. Women of color function at work within a socialstructural context in which they are aware of others' perceptions of them, accordingly adjust their behavior, and modify their self-view as a way of coping. One study on Black women described how career-oriented women see themselves as living in two contexts, one Black and one White. They managed this distinction between their work and personal identities by compartmentalizing the two contexts with rigid boundaries and switching back and forth as needed (Bell, 1990). The distinction of different aspects of the self can cause stress and feelings of estrangement from both identities; feeling detached from one's work self may be more common for women in STEM and could be a factor in retention.

\section{Microaggressions}

The term microaggressions was originally defined by Sue et al. (2007) as verbal, behavioral, or environmental indignities, whether intentional or unintentional, that communicate hostile or derogatory slights and insults toward people of other social groups. While outright harassment due to someone's race or gender is less socially acceptable (albeit commonplace), microaggressions are an example of a subtle form of prejudice. Nearly half of Latinas and Black women in STEM report being mistaken for administrative or custodial staff (Williams et al., 2014). Although the individuals may make these attributions unintentionally, it is nonetheless harmful for the recipient. It is likely that women of color have more frequent experience with microaggressions, which have been linked to a range of negative outcomes including stress and depressive symptoms (Torres, Driscoll, \& Burrow, 2010).

\section{Diversity Climate}

Climate literature points to a link between a favorable diversity climate, job attitudes, and performance (McKay \& Avery, 2015). Diversity climate refers to the organizational context around women and people of color, including perceptions of prejudiced individuals and bias in organizational policies. STEM women of color report being socially excluded more frequently at work, and having less social support than their peers, leading to feelings of isolation and inadequacy (Williams et al., 2014). Working within a favorable diversity climate is unlikely for women of color who face double jeopardy in hostile work experiences-reporting more frequent experiences of inappropriate remarks, harassment, and assault based on race and gender than any other group (Clancy, Lee, Rodgers, \& Richey, 2017). 


\section{Facing Anger Constructively: Future Recommendations}

The overall suggestion presented would be to give intentional consideration of issues of race and ethnicity when studying the social-structural interpretation of gender disparities in STEM. More specific items that may help guide this understanding, theorizing, and practice, are the following:

- Take an interdisciplinary approach: Although our field has largely ignored issues of race and ethnicity or treated them at a surface level, others have made significant advancements. We can borrow from and collaborate with such fields, including counseling psychology, anthropology, womanism, African-American studies, and Latino studies.

- Acknowledge other aspects of identity: Although a focus on race and ethnicity is important in understanding gender disparities, this too oversimplifies the complexity of one's full identity. Issues of class, disability, sexual orientation, and other identities are critical as well within a true intersectional perspective.

- Include women of color in research and theory building: Use communityengaged research methods such as community-based participatory research (CBPR). This approach involves creating equal partnerships between academics and the communities affected by the issues being studied within the research process (Rosenthal, 2016). This is a mutually beneficial approach that can shed light on issues that are typically not studied in psychology.

\section{References}

Bell, E. L. (1990). The bicultural life experience of career-oriented black women. Journal of Organizational Behavior, 11(6), 459-477.

Clancy, K. B., Lee, K., Rodgers, E. M., \& Richey, C. (2017). Double jeopardy in astronomy and planetary science: Women of color face greater risks of gendered and racial harassment. Journal of Geophysical Research: Planets, 122(7), 1610-1623.

Crenshaw, K. (1991). Mapping the margins: Intersectionality, identity politics, and violence against women of color. Stanford Law Review, 43(6), 1241-1299.

DuBois, W. E. B. (1961). The souls of black folk: Essays and sketches. New York: Fawcett Publications.

Lorde, A. (1980). Age, race, class, and sex: Women redefining difference. In M. Anderson \& P. H. Collins (Eds.), Race, class, and gender: An anthology (pp. 495-502). Belmont, CA: Wadsworth.

McKay, P., \& Avery, D. (2015). Diversity climate in organizations: Current wisdom and domains of uncertainty. Research in Personnel and Human Resources Management, 33, 191-233.

Miner, K. N., Walker, J. M., Bergman, M. E., Jean, V. A., Carter-Sowell, A., January, S. C., \& Kanaus, C. (2018). From "her" problem to "our" problem: Using an individual lens versus a social-structural lens to understand gender inequity in STEM. Industrial and Organizational Psychology: Perspectives on Science and Practice, 11(2), 267-290.

National Science Foundation. (2015). Report on women, minorities, and persons with disabilities in science and engineering. Retrieved from https://www.nsf.gov/statistics/2015/nsf15311/start. cfm.

Nkomo, S. M. (1992). The emperor has no clothes: Rewriting "race in organizations." Academy of Management Review, 17(3), 487-513. 
NPR. (2017, October 24). Majority of white Americans say they believe whites face discrimination. National Public Radio, Inc. Retrieved from https://www.npr.org/2017/10/24/559604836/ majority-of-white-americans-think-theyre-discriminated-against

Rockquemore, K. A., Brunsma, D. L., \& Delgado, D. J. (2009). Racing to theory or retheorizing race? Understanding the struggle to build a multiracial identity theory. Journal of Social Issues, 65(1), 13-34.

Rosenthal, L. (2016). Incorporating intersectionality into psychology: An opportunity to promote social justice and equity. American Psychologist, 71(6), 474-485.

Sue, D. W., Capodilupo, C. M., Torino, G. C., Bucceri, J. M., Holder, A., Nadal, K. L., \& Esquilin, M. (2007). Racial microaggressions in everyday life: Implications for clinical practice. American Psychologist, 62(4), 271-286.

Torres, L., Driscoll, M. W., \& Burrow, A. L. (2010). Racial microaggressions and psychological functioning among highly achieving African-Americans: A mixed-methods approach. Journal of Social and Clinical Psychology, 29(10), 1074-1099.

Williams, J. C., Phillips, K. W., \& Hall, E. V. (2014). Double jeopardy? Gender bias against women of color in science. San Francisco, CA: University of California Hastings College of Law. Retrieved from http://www.uchastings.edu/news/articles/2015/01/double-jeopardy-report.pdf

\title{
Intersectionally Insufficient: A Necessary Expansion of the Social-Structural Lens
}

\author{
Stephanie E. V. Brown and Sin-Ning Cindy Liu \\ Texas A\&M University
}

Miner et al.'s (2018) interpretation of gender inequity in STEM fields as a social-structural problem shifts the onus from "her" as the root of the problem to "us" as a society. However, despite noting the "even bleaker" outlook for women of color ${ }^{1}$ early on, the focal article lacks an intersectional focus, ignoring the differential experiences that exist between white women and women of color. Crenshaw's (1991) original work on intersectionality highlighted the fact that the experiences of women of color (WOC) often differ drastically from those of their White counterparts, and the subsequent body of intersectionality literature in a variety of fields reminds us that failing to include an intersectional perspective is an oversight we can no longer afford to make. With this in mind, we highlight the ways in which those at the sity.

Stephanie E. V. Brown, Texas A\&M University; Sin-Ning Cindy Liu, Texas A\&M Univer-

Correspondence concerning this article should be addressed to Stephanie E. V. Brown, Texas A\&M University, 4235 TAMU, College Station, TX 77840. E-mail: stephanieevbrown@tamu.edu

1 The term "women of color" often refers to women who are Black, Latina/Hispanic, Native American/American Indian, Asian, or multiracial. Women of color is an admittedly broad term, and we recognize that experiences of discrimination can vary based on the different socio-political histories that exist between racial and ethnic groups in various countries (Andersen \& Collins, 2011; Johnson, 2011) 